\title{
Effective Computational Techniques of Reducing Cogging Torque in Permanent Magnet Flux Switching Machine
}

\author{
Naseer Ahmad ${ }^{1}$, Faisal Khan ${ }^{2}$, Hamid Ali Khan ${ }^{2}$, Surat Khan ${ }^{1}$, Faizullah Khan ${ }^{1}$, Muhammad Abbas \\ $\mathrm{Khan}^{1}{ }^{\text {,Ishtiaq }}$ Ahmad $^{1}$ \\ ${ }^{1}$ Faculty of Information \& Communication Technology, BUITEMS, Quetta, Pakistan \\ ${ }^{2}$ Department of Electrical and Computer Engineering COMSATS University Islamabad, \\ Abbottabad Campus \\ Corresponding Author: n.ahmadmwt@gmail.com
}

\begin{abstract}
In this paper various techniques are applied to decrease cogging torque of overlap winding of permanent magnet flux switching machine (PMFSM) with 24-slot/16-pole. Due to its unique design PMFSM have mechanical strength, batter torque density and high flux linkage is a suitable candidate for electrical vehicle $(\mathrm{EV})$. The major disadvantage of this design are high cogging torque and torque ripple while keeping constant average torque. Four various techniques are applied to minimalize the cogging torque of PMFSM to design it more suitable for PHEV applications. The legitimacy of these techniques has been observed by 3-D and 2-D simulations. Among all techniques the optimal result of Hybrid_C2 technique which reduces the cogging torque $66.28 \%$ with $0.7 \%$ loss in average torque.
\end{abstract}

Keywords- Cogging torque, skewing, flange, permanent magnet

Date Received 10 Dec 2019

Date Accepted 03 May 2020

Date Published 25 June 2020

\section{INTRODUCTION}

$\mathrm{T}_{\mathrm{e}}^{\mathrm{o}}$ $O$ minimize the usage of fossil fuels and diminish environmental pollution Hybrid Electric Vehicles (HEVs) are used. HEVs is best solution to minimize energy crisis, decrease global warming and $\mathrm{CO}_{2}$ emission [1-5]. Due to maximum utilization of fuels and storage of fuels are decreasing day by day and cost is increasing. Nowadays the research community attracting towards the HEVs due to their exclusive property of using power (electrical) (fuel cells, batteries etc.). Designing of the motor drives necessity have the properties of maximum torque at minimum speed, high power density, low torque ripples and noise, high robustness, minimum cost and must be reliable [6-8]. For the drive machine PHEVs has crucial condition as the flux weakening ability in high speed operation, maximum torque/power density, huge load capacity, efficient thermal intemperance, batter mechanical strength and efficiency [9].

Flux switching permanent magnet machines (FSPMM) have distinctive properties of maximum power density, optimal torque capacity, and rotor robust structure. Due to the compatibility of global warming conditions FSPMM is best choice for the wind applications, aerospace, electric vehicles traction and can also use where ruggedness is concerned [10Journal of Applied and Emerging Sciences Vol (10), Issue (01)
13]. The structure of FSPMM [14] is described by introducing the permanent magnet between two successive slots of stator which further possess the benefit of better temperature control [15].

Two designs of FSPM machine i.e 12-S/7-P and 6-S/14-P were proposed with Overlap Winding $(\mathrm{OW})$ structure which have high performance in term torque density due to larger pitch factor. Using the OW configuration in PM machine decrease harmonic and parasitic effects due to OW [18].

In this paper PMFSM with 24-S /16-P with OW structure is briefly explaining. The main aim of this paper is to reduce the cogging torque by various techniques. Different techniques including: (a) Rotor pole- flange (b) Hybrid technique (c) Skewing (d) pole arc. Detailed examination and analysis of flux linkage, back-EMF, cogging torque, torque ripple, average torque and efficiency have been examined and compared.

\section{COGGING TORQUE OF PMFSM MACHINE}

The interaction between the rotor pole and stator PMs at noload is called cogging torque. Fig.1 depicts the cross section of FSPMM. The FSPMM can be design $b$ an existing coil and PM on stator. Magnetic circuit consists of an existing coil and a PM. The PMFSM total co-energy is calculated as [23-25].

$$
W_{c}=\frac{1}{2} L i^{2}+\frac{1}{2}\left(\mathcal{R}+\mathcal{R}_{m}\right) \varphi_{m}{ }^{2}+N i \varphi_{m}
$$

Where, $\mathcal{R}_{m}, \mathcal{R}$, and $\varphi_{m}$ are reluctances perceived by MMF and the magnetic field, magnetic flux, and magnetorespectively. The average torque can be calculated form Eq. 2 and co-energy is differentiated with respect to mechanical 
angle.

$$
T_{e}=\frac{\partial W_{c}}{\partial \theta} \text { with } i=\text { constant }
$$

Where, $\theta$ and $W_{c}$ are mechanical rotor angle and total coenergy respectively. By solving Eq. 1 and 2, can be calculated electromagnetic torque as:

$$
T_{e}=\frac{1}{2} i^{2} \frac{d L}{d \theta}-\frac{1}{2} \varphi_{m}^{2} \frac{d \mathcal{R}}{d \theta}+N i \frac{d \varphi_{m}}{d \theta}
$$

In Eq. 3 only the 2 nd term is use for cogging torque. Therefore, the cogging torque can be calculated by considering the reluctance variation between the permanent magnet and coil.

$$
T_{\operatorname{cog}}=-\frac{1}{2} \varphi_{g}{ }^{2} \frac{d \mathcal{R}}{d \theta}
$$

Where, $\varphi_{g}$ is airgap flux and with rotating displacement changes occurring in magnetic circuit

$$
\begin{aligned}
W_{c} \approx W_{\text {gap }}=\frac{1}{2 \mu_{0}} \int_{V} B^{2}(\alpha) d V \\
\quad=\frac{1}{2 \mu_{0}} \int_{V} B_{r}{ }^{2}(\alpha) G^{2}(\alpha, \theta) d V
\end{aligned}
$$

Where, $W_{\text {gap }}, \alpha, B(\alpha)$, and $G^{2}(\alpha, \theta)$ are the energy store in airgap, circumference angle of airgap, residual flux density, and flux density rotor to stator respectively. The iron core permeability is much high than the PM and airgap, so neglecting the iron core energy variation. $G^{2}(\alpha, \theta)$ and $B_{r}{ }^{2}(\alpha)$ Fourier expansion are

$B_{r}^{2}(\alpha)=B_{r 0}^{2}+\sum_{m=1}^{\infty} B_{r m} \cos \left(m N_{s} \alpha\right)$

$G^{2}(\alpha, \theta)=G_{0}^{2}+\sum_{n=1}^{\infty} G_{n} \cos \left[n N_{r}(\alpha+\theta)\right]$

Where, $N_{s}$ and $N_{r}$ are the stator pole number and rotor pole number respectively and $B_{r 0}^{2}=\alpha_{s} B^{2}$ res,

$$
B r m=2 \text { Bres }^{2} \frac{\sin \left(m \alpha_{S} \pi\right)}{m \pi}
$$

$\alpha_{s}$ denotes the co-efficient of stator pole arc and Bres is a magnet residual flux density. $G_{n}$ Co-efficient Fourier series expansion as

$$
G_{n}=\frac{2}{\pi} \int_{0}^{\pi} G^{2}(\alpha, \theta) \cos n \theta d \theta
$$

By solving Eq. 5-7 into Eq. 2 to achieve PMFSM cogging torque equation

$$
T_{\text {cog }}(\theta)=\frac{\pi N_{r} L_{s t k}}{4 \mu_{0}}\left(R_{2}^{2}-R_{1}^{2}\right) \sum_{n=1}^{\infty} n G_{n} B_{r n N_{L}} \sin \left(n N_{r} \theta\right)
$$

Where, R1, $L_{s t k}$, and $\mathrm{R} 2$ are the rotor outer radius, stack length, and stator inner radius respectively. Different techniques can be applied on design to reduce cogging torque.

Equation (9) calculated cycle of cogging torque:

$$
\begin{aligned}
N_{p} & =\frac{N_{r}}{H C F\left\{N_{r}, N_{s}\right\}} \\
\text { Pc } & =\frac{N_{p} N_{s}}{N_{r}}
\end{aligned}
$$

Where $\mathrm{N}_{\mathrm{p}}, N_{r}$ and $N_{s}$ consider as a constant, rotor poles and stator slots, number, HCF is highest common factor of $N_{r}$ and $N_{s}$ and Pc for cogging torque period [19].

Journal of Applied and Emerging Sciences Vol (10), Issue (01)

\section{COGGING TORQUE REDUCTION TECHNIQUES}

This technical research paper as an extended version of [22] will provide a specific result analysis of PMFSM with 24-S/16-P with OW. Fig.1 illustrated the PMFSM with OW structure and has maximum cogging torque because due OW winding. The design parameters are summarized in Table 1. In this article, four various state of art techniques are used to minimize cogging torque: rotor- pole -flange, hybrid techniques, skewing, and pole arc as illustrated in Fig. 2.

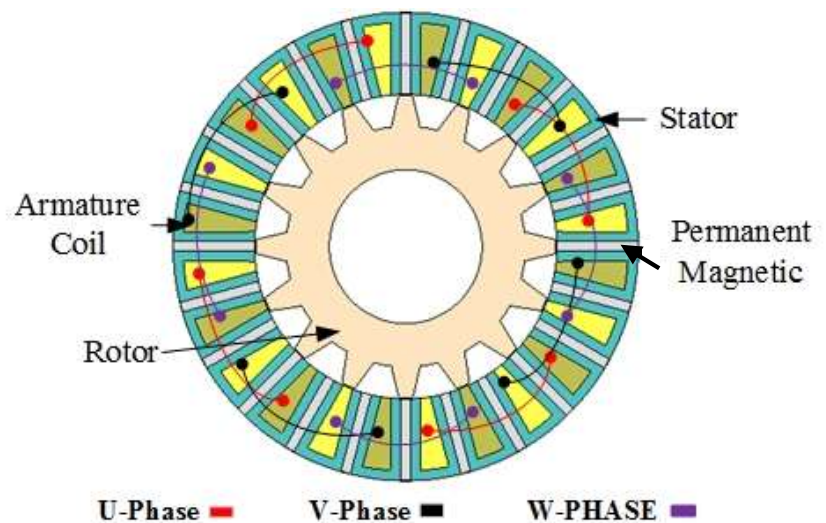

Table 1: Design Parameters

\begin{tabular}{|c|c|}
\hline Design Parameters & Values \\
\hline Phase number, $\mathrm{m}$ & 3 \\
\hline Axial length (mm) & 75 \\
\hline Outer radius of stator (mm) & 64 \\
\hline Air-gap (mm) & 0.35 \\
\hline Number of turn & 70 \\
\hline Pole arc of rotor (degree) & 4.875 \\
\hline Arc of PM (degree) & 3.75 \\
\hline Rotor yoke arc (degree) & 15 \\
\hline Pole arc rotor (degree) & 4.875 \\
\hline Slot arc of Stator (degree) & 3.75 \\
\hline
\end{tabular}

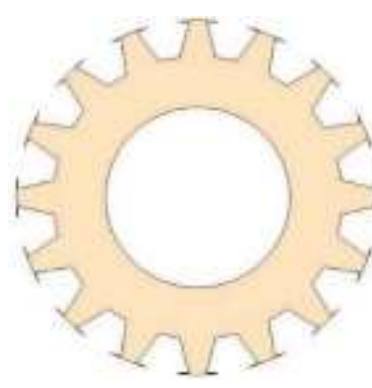

(a)

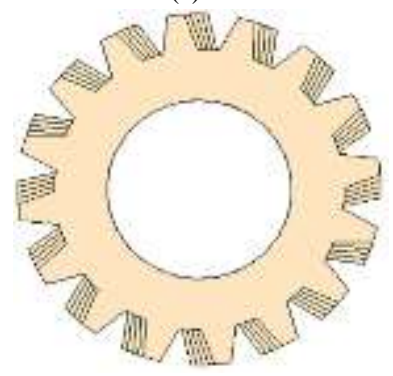

(c)

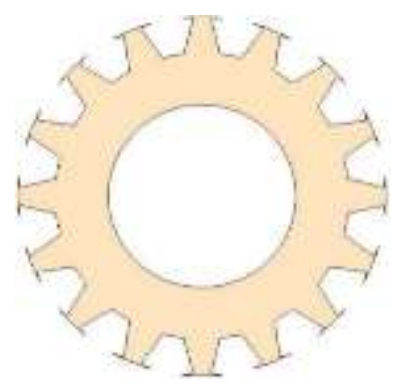

(b)

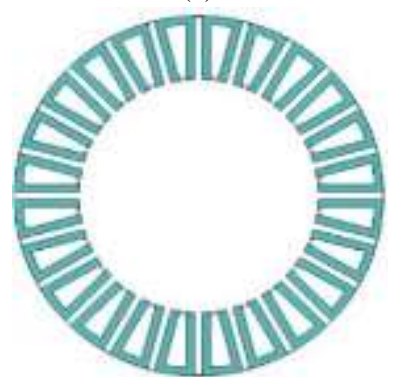

(d)
Fig. 2. (a) Rotor pole- flange (b) Hybrid technique (c) Skewing (d) Pole arc 


\section{DOI: https://doi.org/10.36785/BUITEMS.JAES.324}

\section{A. Rotor Pole-Flange}

The changes in rotor structure can result to minimization in cogging torque and produce a high circumferential area in air gap. [19]. Eq. 4 and 8 clearly illustrated that cogging mainly depend upon the variation of air gap permeance. The flux line making circular shape in airgap where rotor pole and stator teeth are not in align position, that facing high reluctance. To minimizing cogging torque flux line shape are making smooth as possible that can be achieved by adding pole shoe to the rotor pole.

Fig. 3 (a) depicts the initial flux between single rotor pole and single stator pole. The flux line considers to be straight in airgap and circular shape behind the airgap to rotor pole. The permeance equation then becomes [19]:

$$
\begin{gathered}
P=\frac{2 \mu_{0} L_{s t k}}{\pi} \ln \left(\frac{\pi w+2 g+\pi S_{w}}{\pi w+2 h}\right) \\
\text { Reluctance }=\frac{1}{p}=\frac{\pi}{2 \mu_{0} L_{s t k}} \frac{1}{\ln \left(\frac{\pi w+2 h+\pi S_{w}}{\pi w+2 h}\right)}
\end{gathered}
$$

Where, $S_{w}, w, F_{y}$, and FX are the yoke thickness of stator, rotor position, the change occurring with respective to $\theta$ in cylindrical co-ordinates, width of flange, and depth of flange respectively. Therefore, cogging torque is minimizing and due to position of rotor $w$ changed the reluctance of air gap and set to zero to achieve the mandatory condition. Setting reluctance distinguished with respect to position of rotor $w$ is equal to zero, it can illustrate that $S_{w}=0$. This condition is not possible to achieve zero cogging torque form this model without changing geometry. However, to achieving this condition adding flange or pole shoe to the rotor pole as shown in Fig. 3. The pole shoe provides a flux path for every rotor and stator point in result the variation occurring in reluctance with respect to position of rotor. The airgap permeance equation becomes:

$$
\begin{aligned}
P=\frac{\mu_{0} L_{s t k}}{\pi} \ln \left(\frac{\pi w+2 h+\pi F_{y}}{\pi w+2 h-\pi F_{y}}\right) & \\
& +\frac{2 \mu_{0} L_{s t k}}{\pi} \ln \left(\frac{\pi w+2 h+\pi S_{w}+\pi F_{y}}{\pi w+2 h+2 \pi F_{y}}\right)
\end{aligned}
$$

$$
\begin{aligned}
& \mathcal{R}=\frac{1}{p} \\
& =\frac{\pi}{\mu_{0} L_{s t k}} \frac{1}{\ln \left[\left(\frac{\pi w+2 h+\pi F_{y}}{\pi w+2 h-\pi F_{y}}\right) \times\left(\frac{\pi w+2 h+\pi S_{w}+\pi F_{y}}{\pi w+2 h+2 \pi F_{y}}\right)^{2}\right]}
\end{aligned}
$$

Setting $\frac{d R}{d w}=0$, by obtaining the following third order is:

$$
\pi^{2} F^{3}{ }^{2}+F_{y}^{2}\left(3 \pi A+3 \pi^{2} S_{w}\right)+F_{y}\left(2 A^{2}+2 \pi S_{w} A\right)-
$$

$S_{w} A^{2}=0$

Where $A=\pi w+2 h$ is utilized for convenience. It is possible to achieve a condition for Fy in term of " $h$ " and $S_{w}$ for any position of "w", the provides a theoretically zero cogging torque by solving this equation. By solving Eq. $13 \mathrm{~S}_{\mathrm{w}}$; a value of $F_{y}$ can be achieved for a definite value of airgap " $h$ " and stator tooth width and zero reluctance variation is yielded. Hence, zero cogging torque.
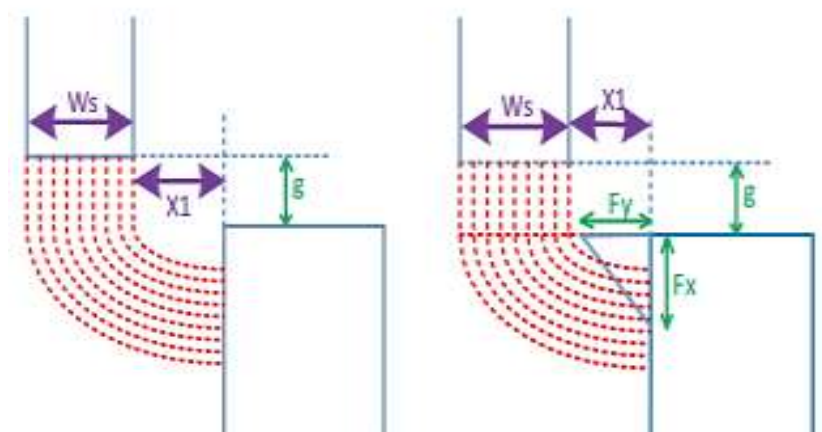

Fig. 3. Flux paths between rotor pole and stator tooth (a) Without flange (b) With flange

Fig. 4 (a) illustrated design view of rotor flange. The simulation results describe the best range flange parameters. Various rotor flange structure is analyzed, the following two design have been illustrated and Fy and Fx are width and height of the flange respectively. The flang_1 with parameters of $F x=0.43 \mathrm{~mm}, F y=2.57 \mathrm{~mm}$ and flang_2 with parameters of $\mathrm{Fx}=0.40, \mathrm{Fy}=1.94 \mathrm{~mm}$. In both design cogging torque is minimized significantly and Fig. 4(b) shows the of flange technique cogging toque.

\section{B. Hybrid Techniques}

Two various techniques are combined at same time to minimized the cogging torque and average torque kept under consideration. Due to higher circumferential area suppress cogging torque by changing rotor poles shape in airgap to increase flux density of magnetic material. Fig. 5 (a) shows Hybrid_N1 which is the grouping of flange and notching and flange and dimensions are achieved after deterministic optimization. The optimize parameter for notch are $h=1.25$, $1=0.4 \mathrm{~mm}$ and for flange are $\mathrm{F}_{\mathrm{y}}=2.57, \mathrm{~F}_{\mathrm{x}}=0.43 \mathrm{~mm}$. Peak to peak cogging torque is reduced up to $20 \%$ due to this combination as illustrated in Fig. 5(c) while electromagnetic torque is just $3.22 \%$ decreased. In second case of Hybrid_C2 in which flange combined chamfering as depicts in Fig. 5(b). The radius of rotor-pole-chamfering is $1.5 \mathrm{~mm}$ with same parameter of flange and approximately $66.3 \%$ reduction occurred in cogging torque and electromagnetic torque effected by $0.7 \%$ as illustrated in Fig. 5(c).

\section{Skewing}

Fig. 6(a) illustrate the skewing technique and skewing one of the best technique to reduce cogging and torque ripples. Skewing of both the rotor, and stator stack can be performed but due to complex structure of stator it is not highly recommended for FSPMM. Skewing has the high order harmonic in back-EMF and make it a sinusoidal wave form. The skewing technique is widely used for cogging torque reduction and it is effective and easy to be implemented but it decreases average electromagnetic torque, high copper losses in case of stator skewing, complex stator construction, stray losses, and increase in inductance leakage have the disadvantages [13]. In this technique the cogging completely reaches to zero theoretically but in practical may not reach to zero but be significantly minimized. Form Fig. 6(b) depicts that cogging torque reduce up to $94.4 \%$ by applying skewing 
technique. The skewing angle [19] between two continuous steps is $1.5^{\circ}$ and total angle is $7.5^{\circ}$ as depicts in Fig. 6(a).

$$
\begin{aligned}
N_{p}=\frac{N_{r}}{H C F\left\{N_{r}, N_{s}\right\}} & \\
\text { Oskew } & =\frac{2 \pi}{\mathrm{nNsNp}}
\end{aligned}
$$

Where, Ns, $\mathrm{n}$, and $\mathrm{Np}$ are the stator slot number, skewing step number and a constant respectively.

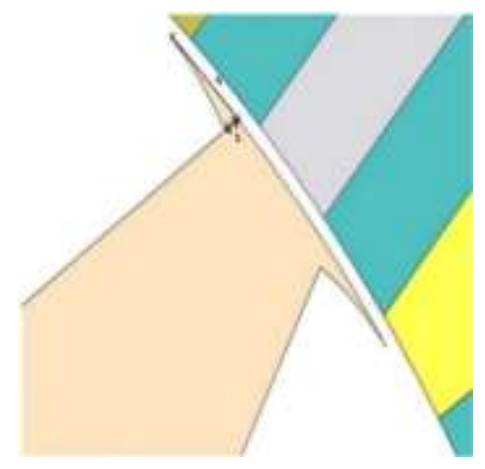

(a)

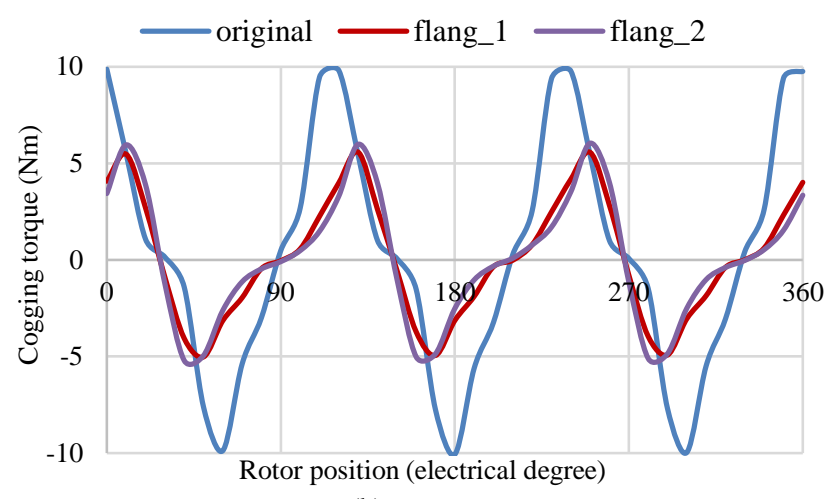

(b)

Fig.4. (a) Rotor-pole-flange (b) Cogging torque

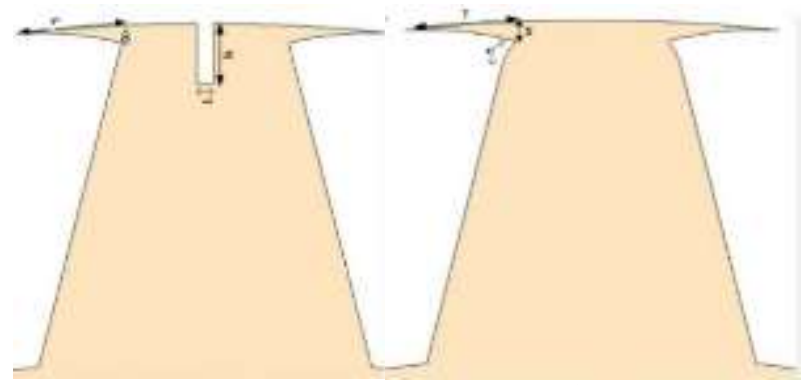

(a)

(b)
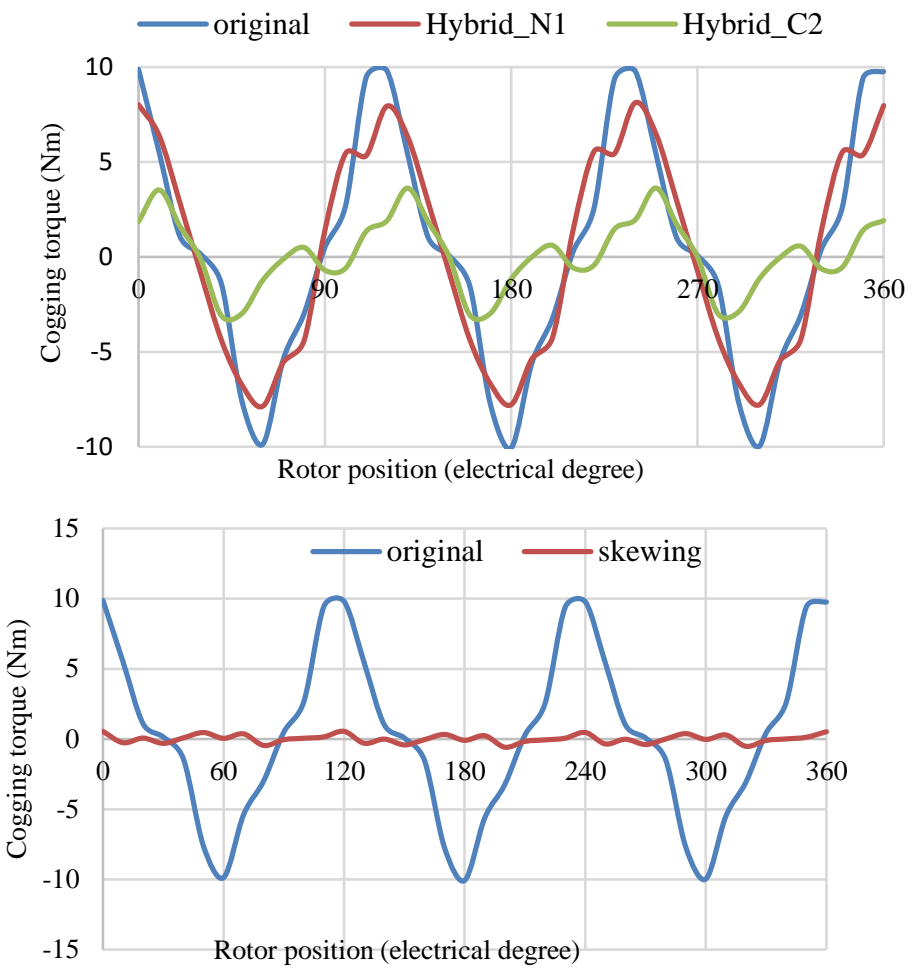

(c)

Fig. 5. (a) Hybrid_N1(b) Hybrid_C2 (c)Cogging torque

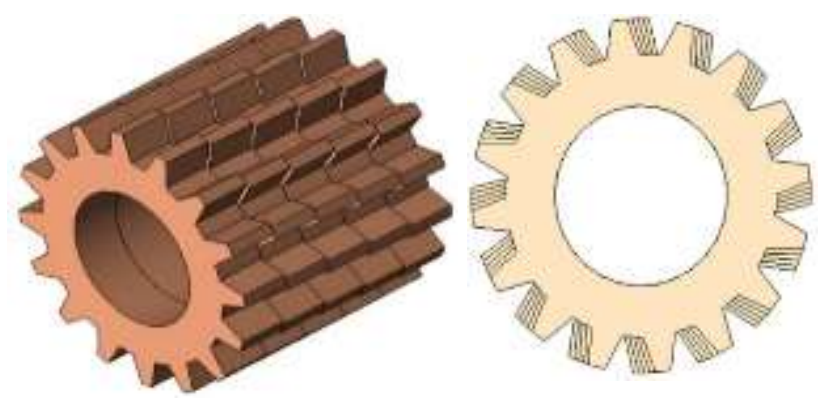

(a)

Fig. 6. (a) Structure view of skewing (b) Cogging torque of skewing

\section{Stator Pole Arc}

Fig. 7(a) depicts the structure view of machine by which applied the stator pole arc technique. Due stator pole arc cogging torque reduction technique, the cogging torque is reduced upto $62.26 \%$ and torque ripple ratio $75.55 \%$ as illustrated in Fig. 7(b). While changing the stator pole arc, the Fourier series of $\mathrm{B}_{\mathrm{rn}}$ can be deduced as [21].

$$
B_{r n}=\frac{2}{n \pi} B_{r}^{2} \sin n \alpha_{p s} \pi
$$

Where $\mathrm{Br}$ and $\alpha_{p s}$ is the residual flux density and pole arc to pole pitch ratio of the stator respectively.

\section{COMPARATIVE STUDY}

\section{A. Cogging torque}

In electrical machine designing the cogging torque is unwanted force in machine which produce vibrations and noise in machine. Various techniques are used to minimized cogging torque. Fig shows comparison between in original/ initial and 
after technique applied cogging torque. Fig. 8 (a) represent the cogging torque and peak-peak value is given in Fig. 8(b). The scheme Hybrid_C2 with cogging torque of $6.73 \mathrm{Nm}$, flang_1 with $10.60 \mathrm{Nm}$ and while the original with the highest $19.94 \mathrm{Nm}$.

\section{B. Average Torque / current}

Fig. 9(a) depicts average torque verses current density at a rated speed of $750 \mathrm{rpm}$ and excitation current is $10.54 \mathrm{~A}$ and torque ripple reduction is illustrated in Fig. 9 (b). Hence, KT is the torque ripple is calculated as:

$$
K_{T}=\frac{\left(T_{\max }-T_{\min }\right) * 100 \%}{T_{\text {avg }}}
$$

Where, $T_{\text {avg }}, T_{\max }$, and $T_{\min }$ are average, maximal and minimal torques in one electrical cycle. It is clear from Fig. that flang_1 has the optimal electromagnetic torque while the least torque ripple in skewing as illustrated in Fig. 9(b).

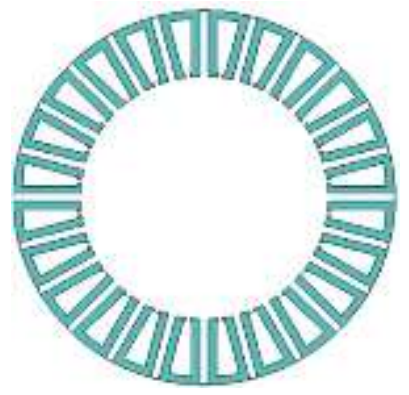

(a)

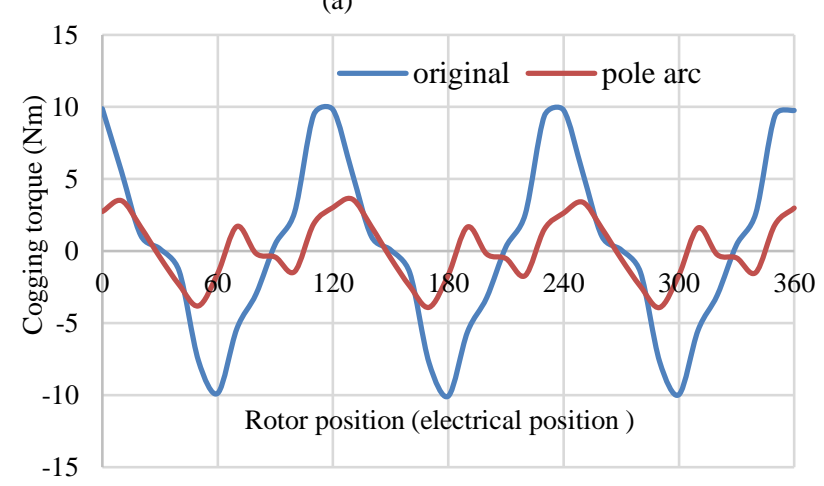

(b)

Fig. 7. (a) Structure view of pole arc (b) Cogging torque of pole arc technique

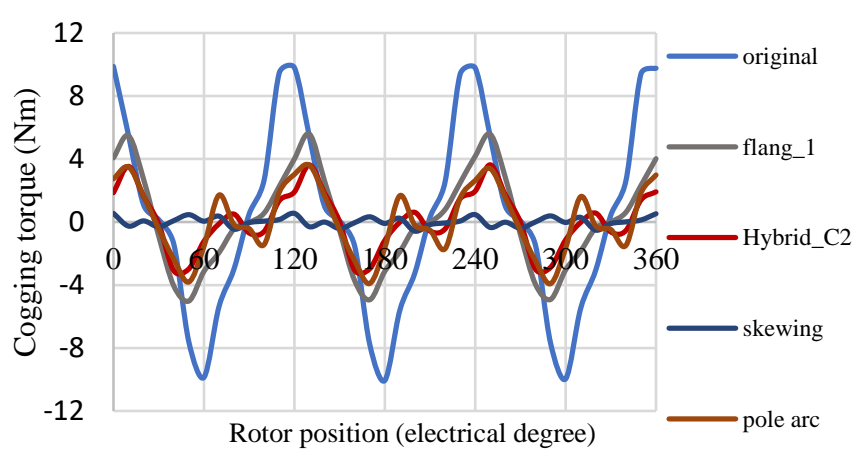

Journal of Applied and Emerging Sciences Vol (10), Issue (01) (a)

(b)

Fig. 8. (a) Cogging torque and (b) Percentage reduction

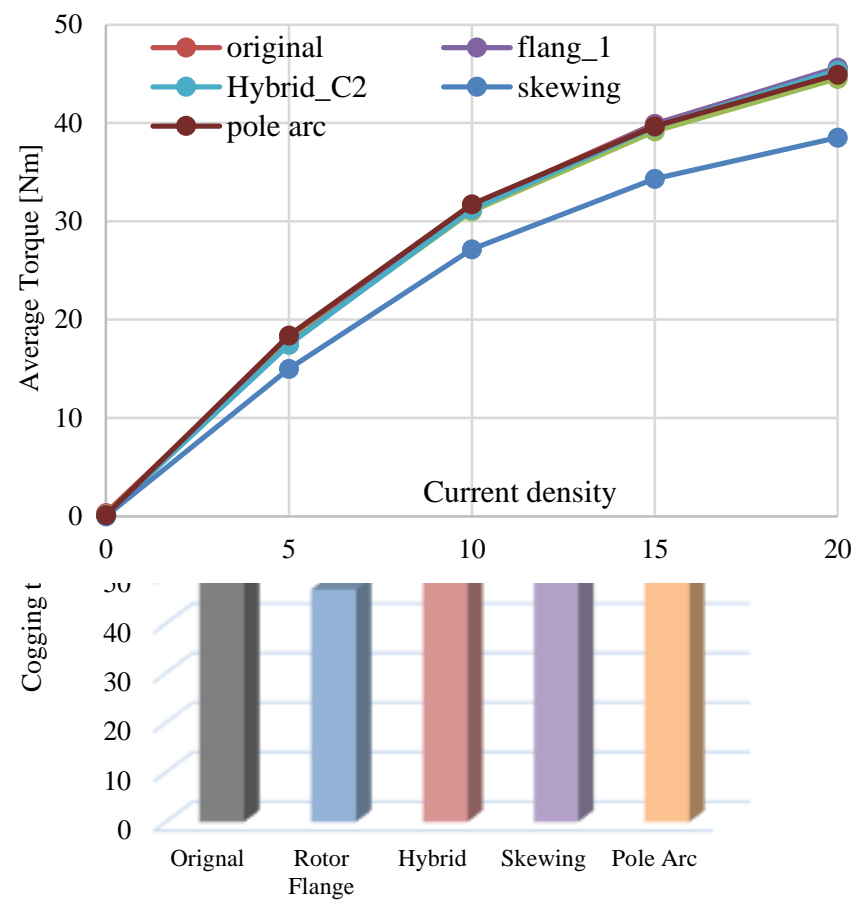

(a)

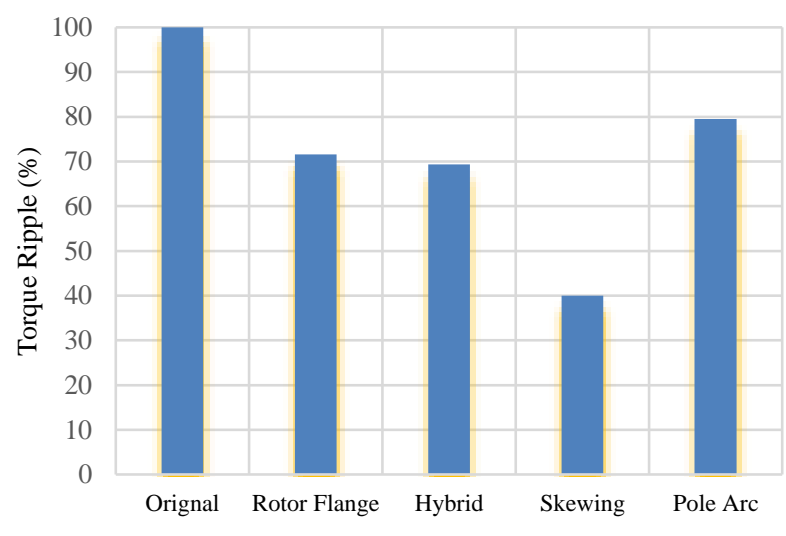

(b)

Fig. 9. (a) Average torque comparison and (b) Torque ripple reduction

\section{Linkage}

Fig. 10 illustrated no load flux linkages only excited due to permanent magnet. In essence, in order to make a clear analysis all flux linkages are combined together. The original design has maximum amplitude as compared with proposed techniques flux linkages. The amplitude of flange is $96.43 \%$ of the original, hybrid has $96.26 \%$, skewing is $84 \%$ and pole arc is $93 \%$ in Fig. 10.

\section{Efficiency}

Losses in machine are the function of load and speed. At 
low-speed the electromagnetic losses are dominate in machine. Three types of power losses in machine are iron losses, copper losses, and mechanical losses (produce by ventilation and frication).

Iron loss is high impact on machine performance, which is calculating precisely. Iron losses are calculated 3D-FEA and 2D- FEA and material is $35 \mathrm{H} 210$ [23-24].

$$
P_{T}=K_{h} B_{\text {Max }}^{2} f+K_{c}\left(B_{\text {max }} f\right)^{2}+K_{e}\left(B_{\max } f\right)^{1.5}
$$

Where $K_{C}, K_{e}, B_{\max }$, and $K_{h}$ are the eddy current loss, coefficient of excess eddy current loss, maximum flux density, and hysteresis loss respectively. Fig. 11 depicts the efficiency bar graph at different cogging torque reduction technique and the original machine efficiency is $85.52 \%$. The maximum and minimum efficiency are $85.51 \%$ and $81.36 \%$ at pole arc and Skewing technique repetitively. The copper losses for all techniques being the same and are calculated as a loss of about 472.18 Watt.

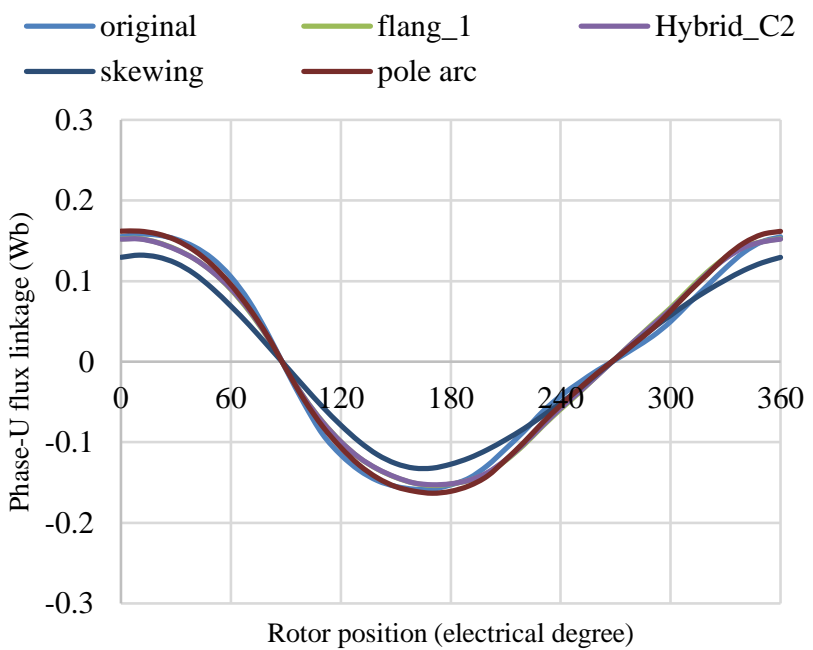

Fig. 10. Flux linkage comparison

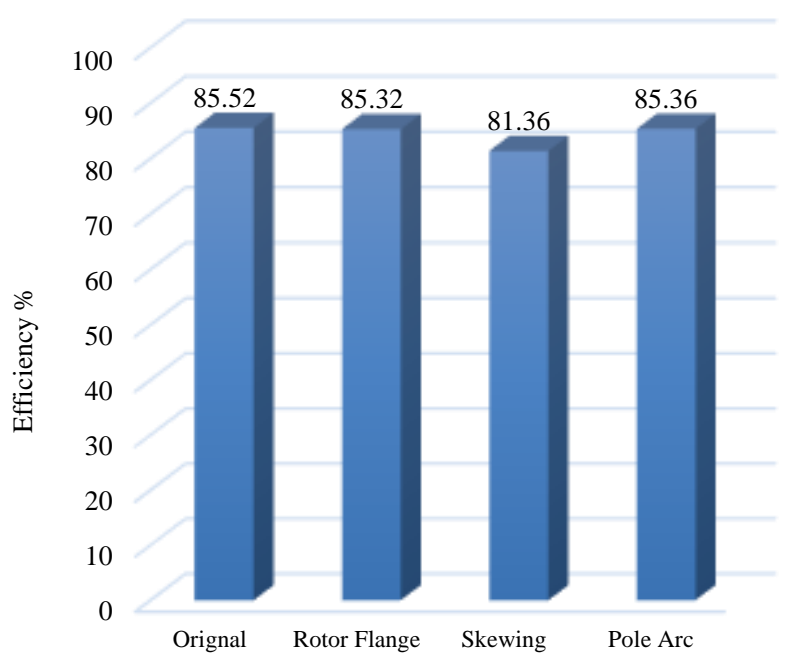

Fig. 11. Efficiency bar graph

\section{CONCLUSION}

Due to plenty of advantage of PMFSM compared with conventional design so PMFSM become an ideal candidate PHEV drive system and in existing design have drawback of high cogging torque in OW-configuration configuration. In this research paper, four various techniques were used to reduce cogging torque in existing design i.e. rotor flange, hybrid, skewing and pole arc. All the 2D- FEA along with 3D-FEA analysis results illustrated that cogging torque was reducing adequately by all of applied techniques. Skewing proved to be the best in reduction of cogging torque but the average torque is reduced to some extent and it also affects rotor saliency.

But the maximum cogging torque lessening and optimal electromagnetic torque was attained by Hybrid method and back-EMF is not disturbed much.

\section{REFERENCES}

[1] W. Fei, P. C. K. Luk, J. X. Shen, Y. Wang, and M. Jin, "A novel permanent-magnet flux switching machine with an outer-rotor configuration for in-wheel light traction applications," IEEE Transactions on Industry Applications, vol. 48, pp. 1496-1506, 2012.

[2] Z. Q. Zhu and D. Howe, "Electrical machines and drives for electric, hybrid, and fuel cell vehicles," Proceedings of the IEEE, vol. 95, pp. 746765, 2007.

[3] M. Z. Ahmad, E. Sulaiman, F. Khan, and Z. A. Haron, "Electromagnetic flux analysis on a new outer-rotor hybrid excitation flux switching machine," in Applied Electromagnetics (APACE), 2014 IEEE AsiaPacific Conference on, 2014, pp. 175-178.

[4] N. Ahmad, F. Khan, A. Rashid, K. Ayaz, and E. Sulaiman. "Rotor pole study of outer rotor wound field flux switching motor for in wheel drive." IEEE International Conference on Computing, Mathematics and Engineering Technologies (iCoMET), 2018, pp. 1-5..

[5] R. Kumar, E. Sulaiman, M. Jenal, L. I. Jusoh, and F. S. Bahrim, "Design and Investigation of Outer Rotor Permanent Magnet Flux Switching Machine for Downhole Application," International Journal of Power Electronics and Drive Systems (IJPEDS), vol. 8, pp. 231-238, 2017.

[6] S. Rauch and L. Johnson, "Design principles of flux-switch alternators," Transactions of the American Institute of Electrical Engineers. Part III: Power Apparatus and Systems, vol. 74, pp. 1261-1268, 1955.

[7] W. Fei, P. Luk, J. Shen, and Y. Wang, "A novel outer-rotor permanentmagnet flux-switching machine for urban electric vehicle propulsion," in Power Electronics Systems and Applications, 2009. PESA 2009. 3rd International Conference on, 2009, pp. 1-6.

[8] S. Othman and E. Sulaiman, "Design study of 3-phase field-excitation flux switching motor with outer-rotor configuration," in Power Engineering and Optimization Conference (PEOCO), 2014 IEEE 8th International, 2014, pp. 330-334.

[9] Z. A. Husin, E. Sulaiman, F. Khan, and M. F. Omar, "Performances comparison of 12S-14P field excitation flux switching motor with overlap and non-overlap windings for hybrid electric vehicles," in Research and Development (SCOReD), 2014 IEEE Student Conference on, 2014, pp. 16.

[10] Z. Q. Zhu and J. Chen, "Advanced flux-switching permanent magnet brushless machines," IEEE Transactions on Magnetics, vol. 46, pp. 1447$1453,2010$.

[11] Y. Wang, M. Jin, W. Fei, and J. Shen, "Cogging torque reduction in permanent magnet flux-switching machines by rotor teeth axial pairing," IET electric power applications, vol. 4, pp. 500-506, 2010.

[12] Z. Q. Zhu, Y. Zhou, and J. Chen, "Electromagnetic performance of nonoverlapping stator wound field synchronous machine with salient pole rotor," IEEE Transactions on Magnetics, vol. 51, pp. 1-4, 2015.

[13] W. Xu, J. Zhu, Y. Zhang, and J. Hu, "Cogging torque reduction for radially laminated flux-switching permanent magnet machine with 12/14 poles," in IECON 2011-37th Annual Conference on IEEE Industrial Electronics Society, 2011, pp. 3590-3595. 


\section{DOI: https://doi.org/10.36785/BUITEMS.JAES.324}

[14] B. Sarlioglu, Y. Zhao, and T. Lipo, "A novel doubly salient single phase permanent magnet generator," in Industry Applications Society Annual Meeting, 1994., Conference Record of the 1994 IEEE, 1994, pp. 9-15.

[15] J. F. Bangura, "Design of high-power density and relatively highefficiency flux-switching motor," IEEE Transactions on Energy Conversion, vol. 21, pp. 416-425, 2006.

[16] T. Raminosoa, C. Gerada, and M. Galea, "Design considerations for a fault-tolerant flux-switching permanent-magnet machine," IEEE Transactions on Industrial Electronics, vol. 58, pp. 2818-2825, 2011.

[17] F. S. Bahrim, E. Sulaiman, L. I. Jusoh, M. F. Omar, and R. Kumar, "Cogging Torque Reduction of IPM Motor using Skewing, Notching, Pole Pairing and Rotor Pole Axial Pairing," International Journal of Applied Engineering Research, vol. 12, pp. 1371-1376, 2017.

[18] C. Sikder, I. Husain, and W. Ouyang, "Cogging torque reduction in fluxswitching permanent-magnet machines by rotor pole shaping," IEEE Transactions on Industry Applications, vol. 51, pp. 3609-3619, 2015.

[19] M. Shen, J. Wu, C. Gan, Y. Hu, and W. Cao, "Cogging torque reduction in FSPM machines with short magnets and stator lamination bridge structure," in Industrial Electronics Society, IECON 2016-42nd Annual Conference of the IEEE, 2016, pp. 4307-4312.

[20] M. Shen, J. Wu, C. Gan, Y. Hu, and W. Cao, "Cogging torque reduction in FSPM machines with short magnets and stator lamination bridge structure," in Industrial Electronics Society, IECON 2016-42nd Annual Conference of the IEEE, 2016, pp. 4307-4312.

[21] L. Shao, W. Hua, Z. Zhu, X. Zhu, M. Cheng, and Z. Wu, "A Novel FluxSwitching Permanent Magnet Machine With Overlapping Windings," IEEE Transactions on Energy Conversion, vol. 32, pp. 172-183, 2017.

[22] S.-M. Hwang, J.-B. Eom, Y.-H. Jung, D.-W. Lee, and B.-S. Kang, "Various design techniques to reduce cogging torque by controlling energy variation in permanent magnet motors," IEEE Transactions on Magnetics, vol. 37, pp. 2806-2809, 2001.

[23] F. Khan, E. Sulaiman, and M. Z. Ahmad, "Review of switched flux wound-field machines technology," IETE Technical Review, vol. 34, pp. 343-352, 2017.

[24] W.-Z. Fei, J.-X. Shen, C.-F. Wang, and P. Chi-Kwong Luk, "Design and analysis of a new outer-rotor permanent-magnet flux-switching machine for electric vehicle propulsion," COMPEL-The international journal for computation and mathematics in electrical and electronic engineering, vol. 30, pp. 48-61, 2011.

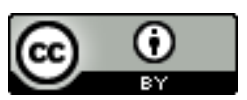
Journal
of
Applied and
Emerging
Sciences by BUITEMS is licensed under a Creative Commons Attribution 4.0 International License. 